\title{
Margarita Barajas Tinoco, Silvia Figueroa Ramírez y José Ascención Moreno Mena (Coords.), Casinos del desierto, juegos de azar y apuestas, México, Universidad Autónoma de Baja California, 2019, 270 pp.
}

Reseña por César Jiménez-Yañez*

Licencia Creative Commons Atribución-NoComercial (CC BY-NC) 4.0 Internacional

Perfiles Latinoamericanos, 28(56) | 2020 | e-ISSN: 2309-4982 DOI: http://doi.org/10.18504/pl2856-016-2020

\section{M}

exicali, capital del estado de Baja California, es una ciudad fronteriza que se ubica al norte de México y que día a día vive el fenómeno de la migración y las dinámicas "normales" de una urbe que comparte una identidad binacional y se comporta de acuerdo a las dinámicas culturales y comerciales que dicta esta vida fronteriza. Es en este contexto donde a tres investigadores (sociólogos todos) adscritos al Instituto de Investigaciones Sociales de la Universidad Autónoma de Baja California les llamó la atención un fenómeno que estaba generando "ruido" social y que no tenía un vínculo directo con la migración. La realidad de una ciudad "no turística” cambiaba aceleradamente su aspecto físico en sus principales arterias y zonas, erigiéndose nuevas construcciones que modificaban la tradicional estética de una urbe plantada en medio del desierto. Nacían los casinos: lugares de juego, apuestas, espectáculos en vivo y diversión —y perdición, para algunos-. Un negocio que el "cachanilla ${ }^{1}$ con visa" conocía y frecuentaba de vez en cuando en el sur de Estados Unidos (California y Arizona).

El crecimiento exponencial de este rubro económico y el cambio en las dinámicas sociales y culturales de una comunidad mexicana fronteriza dio pie a un trabajo académico colegiado, fundado en un proyecto de investigación que comenzó su rodaje en febrero de 2013: Casinos del desierto, juegos de azar

* Doctor en Estudios Socioculturales por la Universidad Autónoma de Baja California (México). Periodista y Licenciado en Comunicación Social por la Universidad de La Frontera (Chile). Docente, investigador y coordinador editorial del Instituto de Investigaciones Culturales-Museo de la Universidad Autónoma de Baja California | jimenez.cesar@uabc.edu.mx

1 Gentilicio popular que se le da a las personas nacidas y residentes en la ciudad de Mexicali. 
y apuestas, un libro de 270 páginas que describe con detalle un mundo lleno de prácticas, simbolismos, códigos, normas, conductas y formas específicas de hacer las cosas donde se involucran la participación y visión de distintos actores vinculados a este mundo del juego y el azar. En resumen, una obra que presenta una radiografía del panorama actual sobre la estructura y funcionamiento de los casinos en la ciudad de Mexicali.

Estamos frente a un libro que, sin hacer una reflexión crítica de fondo del fenómeno sociocultural que representa un casino, nos presenta las posturas política y reglamentaria, y empresarial/administrativa e integra la visión de los empleados y la de los usuarios/clientes respecto a un negocio "nuevo" inserto en una ciudad fronteriza eclipsada por la maquila. Por ello en este libro encontramos investigación documental y de campo, necesarias para documentar y describir de forma específica el proceso de recepción y atención de los clientes de un casino: su llegada, ingreso, compra, juego y consumo. Parte del trabajo metodológico se realizó con base en entrevistas en profundidad realizadas con actores claves, quienes describen procesos contractuales y sus funciones al interior de la empresa. La publicación cierra con la opinión de los clientes/jugadores, quienes exponen su percepción acerca del funcionamiento de estos negocios.

Barajas, Figueroa y Mena dividen este libro en cuatro capítulos, además de una introducción, conclusiones generales y referencias bibliográficas. Uno de los aportes de esta obra, además de explicar histórica y etimológicamente el vocablo "casino", es definir este concepto con las propias palabras de las personas, que son las que lo construyen, se apropian y reproducen el discurso asociado al juego:

- "Para mí los casinos son una forma de distraerme, quitarme el estrés, olvidarme de los problemas y tener la ilusión de ganar."

- "Tomarme una cerveza, pasar el calor, desatontarme, para platicar, para distraerme."

- "Son buenos para las personas que nos gusta jugar o apostar."

Esta es la fortaleza del libro: la descripción y contextualización de un fenómeno nuevo en Mexicali. Los autores explican el funcionamiento de un rubro económico específico que se desarrolla en una ciudad que "no es turística" y que en menos de diez años se ha apoderado de ella con un crecimiento exponencial, apropiándose y reconfigurando el paisaje urbano a través de una oferta de entretenimiento. La debilidad del libro, por así decirlo, radica en la falta de un posicionamiento y planteamiento críticos acerca de un fenómeno sociocultural que se cristaliza en la figura de un centro de entretención y negocio, y que roza varios tópicos de interés social como la migración, las prácticas de consumo, las relaciones laborales y las conductas patológicas (ludopatía), entre otros. Las 
conclusiones generales abren un pequeño espacio para reflexionar acerca de lo que representa el poder del capital y la lógica del capitalismo, pero sin desmenuzar estos conceptos en los capítulos.

En el primer capítulo, "Impacto de los casinos en la reconfiguración urbana de Mexicali”, encontramos un apartado con algunos datos actuales, históricos y anecdóticos sobre la existencia y fundación de los casinos en el país, en el estado y específicamente en Mexicali. Se informa sobre la cantidad de construcciones, la infraestructura disponible, las ubicaciones y los grupos empresariales que están detrás de este lucrativo negocio - la mitad de los casinos en Baja California y Mexicali pertenecen al Corporativo Caliente-. Es necesario detenerse en este punto ya que el libro no aborda el fenómeno empresarial o de participación de mercado que supone ser parte de este negocio, ni las conexiones políticas que existen; si bien enumera los corporativos y se hace mención de un claro conflicto de intereses de un empresario/político en Tijuana, no hay un posicionamiento al respecto. Hubiera sido interesante que se abordaran estos aspectos desde la economía política y haber establecido las redes y conexiones que generan estas estructuras empresariales. A este apartado le sigue otro de carácter conceptual centrado en la reconfiguración urbana y la teoría de la ciudad, en cómo estos espacios urbanos se modifican y la ciudad propone una nueva dinámica social. Esta propuesta teórica se vincula con el nivel político y empresarial, quienes apoyados en el discurso de una "nueva estrategia de desarrollo regional", permiten la aparición de estas "modernas y frescas" estructuras físicas que modifican el paisaje de una ciudad, transformando así los espacios simbólicos y la identidad de una comunidad que debe negociar y apropiarse de un espacio emergente que generará nuevas prácticas culturales y dinámicas sociales asociadas a los nuevos conceptos y discursos que ofrecen estas llamativas estructuras "administradoras del ocio y del entretenimiento".

En el segundo capítulo, "Visión gerencial de los casinos en el escenario de las economías fronterizas", podemos conocer la opinión y el perfil de los gerentes que administran los casinos en Mexicali y cómo estos, a través de distintas estrategias de publicidad, promoción y fidelización, deben mantener vigente un negocio corporativo que carga con un fuerte estigma social, esto es, su relación con el crimen organizado. En este apartado, además de entregarse información técnica asociada al funcionamiento, normatividad y características de los casinos, se presentan las tipologías de un negocio que, de acuerdo a sus administradores, "dinamizan la economía con la creación de empleos, fomento del turismo y el pago de impuestos". La reflexión teórica de este capítulo es menor ya que no profundiza en el perfil de los gerentes inclinándose por el análisis del marketing para clarificar la forma en que este se administra a fin de cumplir con la misión y objetivos del casino: "ser un lugar de entretenimiento que se centra en 
la comodidad, bienestar y permanencia del cliente". Como parte del capítulo, se presenta una cronología sobre la normatividad de este rubro de negocio, lo que ayuda a entender sus procedimientos de seguridad.

En el tercer capítulo, "Puestos de trabajo en los casinos y perfil de los empleados", los autores se adentran en el funcionamiento interno de los casinos y dan cuenta de las dinámicas sociales internas de sus actores (los empleados) a través de conversaciones directas con ellos. Hay un trabajo muy rico de observación y entrevistas que permite darles voz a los empleados. De acuerdo a la información del libro, los casinos generan empleos directos e indirectos según las condiciones específicas del rubro. Para el total de México generan entre 35 mil y 50 mil empleos directos. En Mexicali, generan 2250 de estos puestos de trabajo. En la parte central de este capítulo se describen los perfiles "ideales" de las personas que deben ocupar puestos específicos y el análisis de las características que sugiere la empresa al momento de contratar. Al mismo tiempo, encontramos la opinión de los propios empleados que desempeñan funciones específicas y generales, comentarios por los que podemos conocer un poco más de cómo funciona este "mundito" en el aspecto laboral. Uno de los perfiles profesionales que más llama la atención fue el que se busca para el puesto de dealer o crupier (tallador o repartidor): se requiere que sea rápido en el cálculo mental, tener alto nivel de conocimiento en el cálculo aritmético, capacidad de concentración, seguro de sí mismo, extrovertido, amigable, capaz de trabajar bajo presión, crear una atmósfera relajada, mostrar tacto cuando los jugadores pierden, conocer sobre los distintos juegos, vestir elegantemente, ser honrado y digno de confianza, saber escuchar y explicar, ser organizado, discreto y respetar a las personas. En resumen, y de acuerdo a mi interpretación, se necesitaría a alguien que sea matemático, comunicólogo, psicólogo, sociólogo, filósofo y, quizás, educólogo. Más allá de lo anecdótico de este comentario, el libro describe toda una estructura administrativa jerárquica que, de acuerdo a las entrevistas, se presenta como un buen lugar de trabajo. Todos los trabajadores entrevistados están conformes con las condiciones laborales y la forma en que son tratados por la empresa. A todos se les respetan sus derechos laborales y se les paga en tiempo y forma. Los sueldos, si bien son superiores al salario mínimo, son promedio (no son tan altos), ganan entre 1600 (el runner o vendedor) y 6 mil pesos quincenales (el dealer o repartidor). Y todos, en mayor o menor medida, reciben propinas. La mayoría ha ido escalando en sus empleos dentro de la empresa, trabajan ocho horas diarias y lo más complejo, según ellos, es la forma en que se establecen sus turnos y los descansos.

En el cuarto capítulo y después de conocer cómo nacen, se desarrollan y funcionan los casinos en Mexicali, llegamos a la parte medular del libro: la opinión de las personas que hacen uso de estos espacios y sus servicios. En "Perfil 
y modalidades de consumo de los usuarios clientes de casinos" conocemos de propia voz la opinión que tienen los usuarios de los casinos y al mismo tiempo se caracterizan sus perfiles. La primera parte del capítulo define de modo concreto los conceptos de ocio y tiempo libre, términos asociados a dichos espacios de esparcimiento y entretención. Los casinos ofrecen distintas modalidades de juegos para que la gente "se entretenga", y servicios de comida, bebidas, música $y$, en algunos casos, espectáculos en vivo. De acuerdo al trabajo realizado para el libro, se establece que los usuarios de casinos son en su mayoría mujeres y personas de la tercera edad, y que el gasto promedio de una persona que visita casinos de forma regular en Mexicali es de 500 a 2500 pesos por visita. Sobre todo para los que han ganado en algún momento: "más allá de lo gastado, ganado o perdido, hay un espacio de diversión, de placer, de emoción". Para algunos son lugares de distracción y encuentro: "[...] son lugares para personas de mi edad que buscamos entretenernos y un punto de reunión para el reencuentro con conocidos y con compañeros del trabajo" (p. 179).

Para otros, son lugares en donde se pierde el tiempo, dinero y se genera adicción: "los casinos son la creación más mala que ha hecho el ser humano", "numerosas personas se han engranado tanto en el casino que ahí pierden sueldos, pensiones, cosas importantes", "En el casino se venden varias cosas, como el cuerpo" (p. 181).

Los casinos son la mayor expresión de las premisas del capitalismo: uso individual de los espacios, fomento del interés individual y búsqueda "de forma fácil" de maximizar las utilidades. De ahí que, ya para concluir el capítulo, se abra un espacio para conocer uno de los efectos colaterales quizá más perjudiciales a nivel individual, familiar y social: la ludopatía, el juego patológico. El análisis del libro sobre este aspecto — que da para un análisis aparte- es breve y no se desarrolla a profundidad ya que, de acuerdo a los autores, no es parte del objetivo general del libro. A pesar de lo anterior, dan algunos datos para su definición y entregan información sobre la normativa "presente y/o ausente" en México, que de forma general da cuenta de esta situación como un problema de salud pública creciente. Se cierra este capítulo con el análisis del contenido de una página de Facebook que abre un espacio para la catarsis de jugadores con problemas, rescatando algunas de sus experiencias.

Este libro, como se refiere al inicio, presenta una radiografía actual de los casinos en Mexicali, en términos de su estructura y funcionamiento desde una perspectiva académica, que por momentos se queda solo en la descripción de sus características, en la descripción de los actores relevantes y en las opiniones y declaraciones de sus protagonistas. Si bien esto nos permite conocer más a fondo sobre "este mundo y su realidad" no hay una discusión epistemológica de fondo que nos lleve al análisis más crítico sobre la estructura de un negocio, que por 
sus características tiene vínculos y conexiones políticas de alto nivel. Tampoco se profundiza a nivel teórico sobre el perfil de las personas que administran y acceden a estos "servicios" dejando un vacío para un análisis mayor. Aun así, la obra aporta varios elementos para la comprensión inicial del fenómeno desde disciplinas como la política, la economía, la sociología, el urbanismo y la psicología, para seguir con investigaciones más específicas sobre este rubro y su funcionamiento. Esta obra pasa a ser un documento que aporta a la historia de Mexicali, ya que en sus páginas se encuentra información valiosa que resume los rasgos de una actividad económica que involucra dinámicas locales en lo político, lo empresarial, lo laboral y lo familiar. Un documento académico que se presenta gracias a la curiosidad de sus autores, que vieron en este rubro un problema de investigación que se dieron a la tarea de abordar, y que hoy podemos conocer, analizar y disfrutar. 